\title{
Anxiety Levels Amid the COVID-19 Lockdown in Saudi Arabia
}

\author{
Faisal Mashel Albagmi iD ${ }^{1,2}$ \\ Heba Yaagoub AINujaidi ${ }^{\prime}$ \\ Deema Saad Al Shawan (iD) \\ 'College of Public Health, Imam \\ Abdulrahman Bin Faisal University, \\ Dammam, Saudi Arabia; ${ }^{2}$ The College of \\ Applied Medical Sciences, Imam \\ Abdulrahman bin Faisal University, \\ Dammam, Saudi Arabia
}

\begin{abstract}
Objective: To assess the prevalence of anxiety and factors associated with it during the peak of the outbreak in Saudi Arabia.

Materials and Methods: This cross-sectional research screened the general public using the Generalized Anxiety Disorder Scale-7 to detect anxiety levels. The questionnaire was distributed online during May 2020, while lockdowns were enforced. A total of 3017 respondents from all five main regions of Saudi Arabia completed the survey. The prevalence of anxiety was measured. Chi-square and logistic regression analyses were executed to determine associated factors with anxiety during peak lockdown.

Results: About $19.6 \%$ of the respondents possessed a moderate to severe level of anxiety during the pandemic. Western, Northern, and Eastern regions of Saudi Arabia were found to be the most anxious. Female participants had 5.3\% higher levels of anxiety compared to male counterparts. The youngest age group (18 to 19 years), most of them were students, reported the highest frequency of anxiety (28.7\%). Divorced and single participants had a higher level of anxiety compared to married ones. After adjusted with other variables, living with a family member with risk of the COVID-19 was the best predictor assessing anxiety amid peak lockdown (OR: 1.8, 95\% CI: 1.4-2.2).

Conclusion: Notable anxiety prevailed during the initial phase of the COVID-19 outbreak in Saudi Arabia. The presence of vulnerable subjects in the family augments this psychological disorder considerably. Our findings promulgate a need to inculcate nation-wide strategies to enforce public health emergency preparedness plans to mitigate the adverse psychological effects of outbreaks.
\end{abstract}

Keywords: COVID-19, psychological impact, anxiety disorder, prevalence, Saudi Arabia

\section{Introduction}

One of the unprecedented threats of the COVID-19 pandemic is the potential emergence of a public mental health crisis that eventuates from a destabilized sense of public safety and market economy. Lifestyle altering measures intended to curb the spread of the virus may further exacerbate anxiety levels as it affects many facets of everyday life, and the psychological impact within the different sectors of society is scantily understood. ${ }^{1}$

The pandemic reached Saudi Arabia's doorsteps on March 2, 2020, after a Saudi citizen traveled from Iran and tested positive for COVID-19. Subsequently, the number of confirmed cases and deaths rapidly escalated amid growing fears. ${ }^{2}$ During that period, the most drastic measures to limit the spread were the enforcement of partial curfews and lockdowns. Partial lockdowns were imposed between April 21, and May 11, which allowed citizens and residents to leave their homes
Correspondence: Deema Saad Al Shawan College of Public Health, Imam Abdulrahman Bin Faisal University,

Dammam, Saudi Arabia

Email dshawan@iau.edu.sa 
between 6 am and $6 \mathrm{pm}$. Subsequently, during the pandemic's peak, 24-hour curfews were enacted in the Kingdom from May 23 to May 27. The lockdowns mandated that everyone remained in their homes except for individuals going out to purchase necessities during the day and essential workers with permits. ${ }^{3}$

Most studies on the psychological response to the outbreak were predominantly conducted in China, where the virus originally emerged. For instance, a cross-sectional study conducted by Wang, Pan, and Wan et al, 2020 in China measured the general public's immediate psychological response during the initial stage of the outbreak. This study assessed the COVID-19 impact on mental health by employing a self-administered questionnaire, Impact of Event Scale-Revised (IES-R), that aims to evaluate the level of psychological impact one-week post-exposure to a public health crisis. The researchers also utilized the Depression, Anxiety, and Stress Scale (DASS-21) to measure respondents' mental health status. Wang et al, 2020 reported that

$53.8 \%$ of respondents rated the psychological impact of the outbreak as moderate or severe; $16.5 \%$ had moderate to severe depressive symptoms, $28.8 \%$ had severe anxiety symptoms, and $8.1 \%$ had moderate to severe stress levels. ${ }^{4}$

The researchers concluded their study by identifying possible factors that can alleviate the psychological impact of the COVID-19 outbreak by engendering accessible educational content and precautionary measures relating to the virus's management. ${ }^{4}$

Other studies investigated the ongoing pandemic's psychological impact on Chinese health care workers. Lai et Ma and Wang al., 2020 conducted a survey-based crosssectional study that empirically quantified severe depressive symptoms, insomnia, anxiety, and other symptoms of distress from a total of 1257 health care workers. According to the authors, $50.4 \%$ of participants demonstrated symptoms of depression, $44.6 \%$ suffered from anxiety, 34\% had insomnia, and $71.5 \%$ were categorically distressed. The study concluded by identifying three characteristics that affected the mental health outcomes of health care providers, including the sex of the health care practitioner, geographical proximity to the epicenter of the outbreak, and the degree of interaction with COVID-19 patients. $^{5}$

Additionally, similarly to this study, published research worldwide aimed to measure anxiety levels during COVID-19 lockdowns. For instance, a survey study conducted in Russia surveyed 352 participants during the fourth week of the lockdown between 22 and 27 April 2020. According to the results, higher than average anxiety levels were detected in $29.83 \%$ of the respondents, and $16.76 \%$ reported higher levels of depression. Moreover, the respondents attributed their lowered mental status to potential future financial issues, distribution to their daily lives, and concerns for the health of their relatives who are elderly and chronically ill. ${ }^{6}$

As for the public's psychological response during the COVID-19 pandemic in Saudi Arabia, some studies focused on assessing the mental health effects of the pandemic on specific populations. For instance, Temsah and colleagues, conducted a cross-sectional study on the impact of COVID-19 on health care professionals compared to the impact of the Middle East respiratory syndrome coronavirus (MERS-CoV). They surveyed 811 health care providers working at a tertiary teaching hospital in Riyadh, Saudi Arabia, between February 5th and 16th, 2020. The survey utilized the GAD-7 (Generalized Anxiety Disorder-7) self-reported screening measure to assess GAD's prevalence. Since the data were collected before any COVD-19 cases were confirmed, the survey included questions about the participant's prior exposure to MERS-CoV and their COVID-19 knowledge and concerns. Temsah and his colleague reported that the novel coronavirus's anxiety was higher than previous outbreaks despite data being collected before any confirmed cases. ${ }^{7}$

A cross-sectional study by Arafa measured levels of stress, anxiety, and depression among another specific population: frontline healthcare workers in Saudi Arabia and Egypt. The total sample included 426 health care workers, 151 from Saudi Arabia and 275 from Egypt, $48.4 \%$ of the total population were physicians, $24.2 \%$ were nurses, and $27.4 \%$ were other types of health care providers. The study results reported that $69 \%$ of participants depression 58.9\% had anxiety, 55.9\% had stress, and $37.3 \%$ suffered from inadequate sleep. ${ }^{8}$ Additionally, health care professionals in Egypt had higher rates of depression, anxiety, and stress, which could be attributed to the higher number of emergency and night shifts. The study concluded by emphasizing the importance of psychological support and counseling for frontline health care workers.

Another study measured the psychological impact of COVID-19 during the early stages of the pandemic in Saudi Arabia. ${ }^{9}$ The study included a total of 1160 participants; about $23.6 \%$ reported moderate or severe 
psychological impact while $28.3 \%, 24 \%$, and $22.3 \%$ reported moderate to severe depressive, anxiety, and stress symptoms, respectively. The authors concluded that onefourth of the sampled population reported moderate or severe psychological effects during the pandemic's early stages.

Nonetheless, the complete lockdowns' psychosocial impact is not fully understood due to limited research globally. For that reason, this exploratory study represents the first conducted research that has assessed the prevalence of the Generalized Anxiety Disorder (GAD) across Saudi citizens and residents during the peak of the COVID-19 outbreak (May 11 to May 26, 2020). Additionally, this research aimed to provide a sociodemographic profile of the anxiety levels within Saudi Arabia. This study's results could yield critical and pertinent information to policy decision-makers to further develop targeted, evidence-based interventions to limit the insidious impacts of the pandemic on mental health.

\section{Materials and Methods}

This cross-sectional study was conducted on the general public living in Saudi Arabia during the COVID-19 outbreak. Participants from each of the 13 regions in Saudi Arabia were recruited to assess their Generalized anxiety disorder (GAD) levels during the COVID-19 pandemic.

The GAD-7 survey was utilized for rapid screening of probable cases of GAD. ${ }^{10}$ The searchers adopted an Arabic version of the GAD-7 survey translated and validated by a study conducted in Lebanon by Sawaya and his colleagues. ${ }^{11}$ Also, the GAD-7 survey was validated by Sawaya et al, 2016 to ensure its applicability to the Saudi context. $^{12}$ The questionnaire consisted of three parts; the first part was comprised of the questions to identify demographic information, the second part asked potential factors associated with anxiety levels, and the 3rd part contained seven items of the GAD-7 tool.

The thirteen administrative regions were later merged into five main regions: the Middle Region, Eastern Region, Western Region, Northern Region, and Southeast Region.

An online questionnaire was developed using Question pro and was distributed through a snowball sampling strategy. An online survey was initially distributed through Sharek Health, an organization that aids in data collection in all Saudi Arabia regions. Subsequently, the survey was shared via Twitter and WhatsApp, and they were asked to pass it on to others. The inclusion criteria were any Saudi citizens or residents 18 years old or older and completed the study survey with no exceptions. A pilot study was conducted to evaluate study instruments' feasibility and adequacy to ensure face and content validity. Based on the participants' feedback, minor changes were made to the answer scale for some demographic questions.

Ethical approval was taken from the Institutional Review Board of Imam Abdulrahman Bin Faisal University (IRB-2020-03-153). Respondents were asked to complete the online questionnaire to screen for anxiety levels using the Generalized Anxiety disorder (GAD-7). The reliability of GAD-7 in screening anxiety is reported in the previous literature as excellent (Cronbach $\alpha=$ 0.92). ${ }^{10}$ The collection of responses using QuestionPro was active for 15 days from May 11 to May 26, 2020. The selection of this period was made as major policies were implemented during this period, such as the enforcement of curfews, travel restrictions, and quarantine.

Descriptive measures of the variables are expressed with frequency and percentage. The reliability of the GAD-7 scale was calculated using Cronbach's alpha test. To assess anxiety level, first, the sum of 7 items of GAD-7 was obtained. The anxiety score was ranging from 0 to 21 , with 0-3 points for each of the seven questions. Participant scores ranging from ${ }^{5,7-10}$ were considered mild, ${ }^{1-15}$ as moderate, and $(>15)$ as severe. Both moderate and severe are labeled as the presence of possible clinically significant anxiety. ${ }^{13}$

To measure the prevalence of anxiety, we divided the number of participants who scored moderate to severe level of anxiety from the number of participants completed the survey. Bivariate analysis was conducted using a chisquare test of association between the presence of anxiety and participants characteristics. P-value less than 0.05 was considered as the threshold for statistically significant results. Univariable and multivariable logistic regression analyses were run to study the effect of participants' characteristics on the presence of anxiety. Variables that showed significant effect at univariable stage were further adjusted in the multivariable analysis. Results are reported with odds ratio and 95\% confidence interval.

\section{Results \\ Survey Responses}

A total of 7725 respondents viewed the questionnaires during the two weeks of study; 3929 attempted to fill out the questionnaire. Among them, 779 partially answered, while 3017 completed the survey questionnaire. The 
participants who fully completed the survey were included in this analysis.

\section{Participants}

The highest response was obtained from the Eastern region (51.9\%), followed by the middle region (29.9\%). Most of the participants were from the education sector $(n=352$, $34.6 \%) .196$ (19.3\%) belonged to the health sector. Onethird (33\%) were males, more than half were between age group 20-39 years $(n=1689,56 \%)$ and married $(n=989$, $63.7 \%)$. Most of the participants were graduates $(61.1 \%)$, employees (46.9\%), and working from home (40.7\%). A quarter of families had less than five household members $(\mathrm{n}=377,24.1 \%)$, while 5-9 household members were reported by 970 (62\%). The increased risk of COVID-19 by any household member was alarmed by more than onethird of respondents $(\mathrm{n}=575,36.7 \%)$ (Table 1).

\section{Anxiety Levels}

The rapid screening for the generalized anxiety disorder levels using the GAD-7 questionnaire identified that $80.4 \%$ of respondents had mild anxiety, $11.4 \%$ had moderate anxiety, and $8.2 \%$ had severe anxiety. Following the GAD-7 developers' instructions, the participant with moderate and severe anxiety will be labeled as the presence of possible clinically significant anxiety. Hence, anxiety prevailed among 592 (19.6\%) Saudi population during the outbreak of COVID-19. The reliability of the GAD-7 from our survey showed that the responses were highly consistent (Cronbach's alpha $=0.89$ ).

\section{Association of Anxiety with Participants Characteristics}

Looking at the frequency of anxiety among different regions, it was observed that although the Southeast region was the highest in enduring severe anxiety (9.3\%), the Northern and Western regions were the lowest in observing mild anxiety (76.8\%). The middle region was found to be least anxious (Figure 1)

Table 2 displays the association of participants' characteristics on the presence of anxiety. Among the regions, the Western and Northern regions were the most anxious with other regions $(\mathrm{P}=0.003)$. The presence of anxiety was not significantly different among different sectors
Table I Descriptive Characteristics of the Participants

\begin{tabular}{|c|c|c|c|}
\hline & & $\mathbf{n}$ & $\%$ \\
\hline \multirow[t]{5}{*}{ Geographical region } & Middle region & 903 & $29.9 \%$ \\
\hline & Eastern Region & 1565 & $51.9 \%$ \\
\hline & Western region & 246 & $8.2 \%$ \\
\hline & Northern region & 185 & $6.1 \%$ \\
\hline & Southeast region & 118 & $3.9 \%$ \\
\hline \multirow[t]{7}{*}{ Sector } & Health sector & 407 & $20.7 \%$ \\
\hline & Education & 648 & $33.0 \%$ \\
\hline & Energy & 118 & $6.0 \%$ \\
\hline & Finance/ & 177 & $9.0 \%$ \\
\hline & Communication/ & & \\
\hline & Armed forces & & \\
\hline & Other & 614 & $31.3 \%$ \\
\hline \multirow[t]{2}{*}{ Gender } & Male & 1327 & $44.0 \%$ \\
\hline & Female & 1690 & $56.0 \%$ \\
\hline \multirow[t]{6}{*}{ Age } & $18-19$ & 132 & $4.4 \%$ \\
\hline & $20-29$ & 830 & $27.5 \%$ \\
\hline & $30-39$ & 859 & $28.5 \%$ \\
\hline & $40-49$ & 550 & $18.2 \%$ \\
\hline & $50-59$ & 468 & $15.5 \%$ \\
\hline & 60 and above & 178 & $5.9 \%$ \\
\hline \multirow[t]{3}{*}{ Marital Status } & Single & 954 & $31.6 \%$ \\
\hline & Married & 1956 & $64.8 \%$ \\
\hline & Divorced/Widowed & 107 & $3.5 \%$ \\
\hline \multirow[t]{4}{*}{ Education level } & School education & 481 & $15.9 \%$ \\
\hline & Diploma & 254 & $8.4 \%$ \\
\hline & Bachelor & 1814 & $60.1 \%$ \\
\hline & Postgraduate & 468 & $15.5 \%$ \\
\hline \multirow[t]{6}{*}{ Occupation } & Student & 488 & $16.2 \%$ \\
\hline & Employee & 1476 & $48.9 \%$ \\
\hline & Freelancer & $|4|$ & $4.7 \%$ \\
\hline & Housewife & 376 & $12.5 \%$ \\
\hline & Retired & 348 & $11.5 \%$ \\
\hline & Unemployed & 188 & $6.2 \%$ \\
\hline \multirow[t]{4}{*}{$\begin{array}{l}\text { Work or study procedure } \\
\text { after COVID-19 outbreak }\end{array}$} & $\begin{array}{l}\text { Working from the } \\
\text { office }\end{array}$ & 568 & $27.0 \%$ \\
\hline & Working from home & 832 & $39.5 \%$ \\
\hline & In paid Vacation & 271 & $12.9 \%$ \\
\hline & Studying from home & 434 & $20.6 \%$ \\
\hline \multirow[t]{3}{*}{ Household member } & $<5$ & 674 & $22.3 \%$ \\
\hline & $5-9$ & 1869 & $61.9 \%$ \\
\hline & $>9$ & 474 & $15.7 \%$ \\
\hline \multirow[t]{2}{*}{ Anxiety } & $\begin{array}{l}\text { Clinically } \\
\text { insignificant }\end{array}$ & 2425 & $80.4 \%$ \\
\hline & Clinically significant & 592 & $19.6 \%$ \\
\hline
\end{tabular}




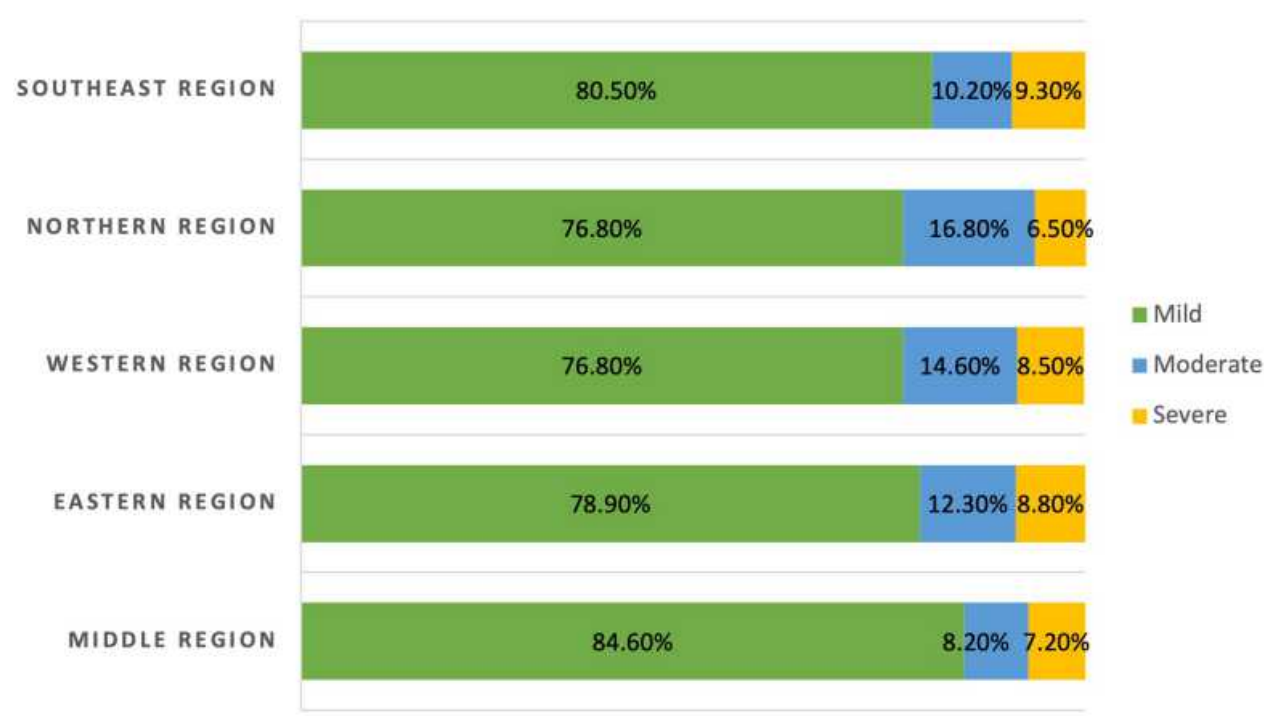

Figure I Anxiety level among different regions of Saudi Arabia. The $y$-axis shows the region, while the $x$-axis shows the percentages of anxiety in different regions. The green bar indicates mild anxiety, the blue bar indicates moderate anxiety, and the yellow bar indicates severe anxiety.

$(\mathrm{P}=0.121)$. The participants' age played a significant role in anxiety among Saudi residents during the first wave of the pandemic $(\mathrm{P}<0.001)$.

A quarter of single participants were found as anxious $(\mathrm{n}=242,25.4 \%)$ while about each 1 in 5 divorced/widowed participants reported a significant level of anxiety $(n=21$, $19.6 \%$ ). The association between marital status and anxiety was statistically significant $(\mathrm{P}<0.001)$.

Education level did not play a significant role in anxiety during the pandemic $(\mathrm{P}=0.542)$. The proportion of anxiety in students was the highest $(27.5 \%)$, followed by employee $(20.3 \%)$ and housewife $(19.9 \%)(\mathrm{P}<0.001)$. A quarter of participants working from the office were anxious $(\mathrm{n}=145,25.5 \%)(\mathrm{P}<0.001)$.

A different number of household members did not significantly affect the anxiety during COVID-19 pandemic onset $(\mathrm{P}=0.878)$. Having vulnerable household members showed a significant association with the presence of anxiety $(\mathrm{P}<0.001)$.

\section{Factors Affecting Anxiety Among Participants}

We ran unadjusted and adjusted logistic regression to see the effect of participants' characteristics on anxiety, as displayed in Table 3. Compared with the middle region, the two regions had a $70 \%$ more chance of anxiety in unadjusted analysis. The Eastern region's odds ratio was 1.5 (95\% CI: 1.2-1.8), which implied the Eastern region was $50 \%$ more anxious than the middle region. Females were $40 \%$ more anxious than males (OR: 1.4 , 95\% CI: 1.2-1.7). They observed a decreasing trend with the proportion of anxiety with increased age. The teenager group (age 18-19 years) was 5.6 times more anxious than senior citizens (Age 60+ years). Similarly, age groups 20-29 years and 30-39 years were four times more anxious than senior citizens. Also, the age group 50-59 years was almost twice as anxious as the senior citizens. Compared with the single participants, married were $40 \%$ and widowed/divorced were 30\% less anxious.

Students were twice as significantly anxious as those not currently employed, such as unemployed, homemakers, and retired (OR: 2.14, 95\% CI: 1.66-2.80). Employed were $44 \%$ more anxious than the not currently employed individuals (OR: 1.44, 95\% CI: 1.16-1.80). Those working from home were $50 \%$ less anxious than those working from the office (OR: 0.5 , 95\% CI: $0.42-$ 0.71). Also, those studying from home were $10 \%$ more anxious than them (OR:1.1, 95\% CI: 0.85-1.5).

Participants who reported the presence of any household member with an increased risk of COVID19 were nearly twice as anxious as those who did not have any such household members (OR: 1.8, 95\% CI: 1.5-2.2).

Adjusted analysis using multivariable logistic regression depicted that any household member under increased risk of COVID-19 demonstrated to be a significant predictor of anxiety among the Saudi population during the first wave of the pandemic. 
Table 2 Association of Anxiety with Participants Characteristics

\begin{tabular}{|c|c|c|c|c|}
\hline & & $\begin{array}{l}\text { Anxiety } \\
\text { Present }\end{array}$ & $\begin{array}{l}\text { Anxiety } \\
\text { Absent }\end{array}$ & P-value \\
\hline \multirow[t]{5}{*}{ Geographical region } & Middle & $764(84.6 \%)$ & 139 (15.4\%) & $0.003 *$ \\
\hline & Eastern & 1235 (78.9\%) & $330(21.1 \%)$ & \\
\hline & Western & $189(76.8 \%)$ & $57(23.2 \%)$ & \\
\hline & Northern & $142(76.8 \%)$ & $43(23.2 \%)$ & \\
\hline & Southeast & $95(80.5 \%)$ & $23(19.5 \%)$ & \\
\hline \multirow[t]{6}{*}{ Sector } & Health sector & 305 (74.9\%) & $102(25.1 \%)$ & 0.121 \\
\hline & Education & $527(81.3 \%)$ & $121(18.7 \%)$ & \\
\hline & Energy & 89 (75.4\%) & $29(24.6 \%)$ & \\
\hline & Finance/Communication/Armed & $136(76.8 \%)$ & $4 \mathrm{I}(23.2 \%)$ & \\
\hline & forces & & & \\
\hline & Other & $473(77.0 \%)$ & $14 \mid(23.0 \%)$ & \\
\hline \multirow[t]{2}{*}{ Gender } & Male & II 06 (83.3\%) & $221(16.7 \%)$ & $<0.00 I^{*}$ \\
\hline & Female & $1319(78.0 \%)$ & $37 \mathrm{I}(22.0 \%)$ & \\
\hline \multirow[t]{6}{*}{ Age } & $18-19$ & 94 (7I.2\%) & $38(28.8 \%)$ & $<0.00 I^{*}$ \\
\hline & $20-29$ & $625(75.3 \%)$ & $205(24.7 \%)$ & \\
\hline & $30-39$ & $664(77.3 \%)$ & 195 (22.7\%) & \\
\hline & $40-49$ & $46 \mathrm{I}(83.8 \%)$ & $89(16.2 \%)$ & \\
\hline & $50-59$ & $415(88.7 \%)$ & 53 (II.3\%) & \\
\hline & 60 and above & $166(93.3 \%)$ & $12(6.7 \%)$ & \\
\hline \multirow[t]{3}{*}{ Marital Status } & Single & $712(74.6 \%)$ & $242(25.4 \%)$ & $<0.00$ I* \\
\hline & Married & $1627(83.2 \%)$ & $329(16.8 \%)$ & \\
\hline & Divorced/Widowed & $86(80.4 \%)$ & $21(19.6 \%)$ & \\
\hline \multirow[t]{4}{*}{ Education level } & School education & $380(79.0 \%)$ & $101(21.0 \%)$ & 0.542 \\
\hline & Diploma & $211(83.1 \%)$ & $43(16.9 \%)$ & \\
\hline & Bachelor & $1453(80.1 \%)$ & 361 (19.9\%) & \\
\hline & Postgraduate & 381 (8I.4\%) & $87(18.6 \%)$ & \\
\hline \multirow[t]{6}{*}{ Occupation } & Student & 354 (72.5\%) & 134 (27.5\%) & $<0.00 I^{*}$ \\
\hline & Employee & $1176(79.7 \%)$ & $300(20.3 \%)$ & \\
\hline & Freelancer & $120(85.1 \%)$ & $21(14.9 \%)$ & \\
\hline & Housewife & $301(80.1 \%)$ & 75 (19.9\%) & \\
\hline & Retired & 317 (91.1\%) & 31 (8.9\%) & \\
\hline & Unemployed & $157(83.5 \%)$ & $31(16.5 \%)$ & \\
\hline \multirow[t]{4}{*}{ Work or study procedure after COVID-19 outbreak } & Working from the office & $423(74.5 \%)$ & 145 (25.5\%) & $<0.00 I^{*}$ \\
\hline & Working from home & $701(84.3 \%)$ & $13 \mid(15.7 \%)$ & \\
\hline & In paid Vacation & $213(78.6 \%)$ & $58(21.4 \%)$ & \\
\hline & Studying from home & $313(72.1 \%)$ & I2I (27.9\%) & \\
\hline \multirow[t]{3}{*}{ Household member } & $<5$ & $540(80.1 \%)$ & 134 (19.9\%) & 0.878 \\
\hline & $5-9$ & $1500(80.3 \%)$ & 369 (19.7\%) & \\
\hline & $>9$ & $385(81.2 \%)$ & $89(18.8 \%)$ & \\
\hline \multirow{2}{*}{$\begin{array}{l}\text { Any household member under increased risk of } \\
\text { COVID-19? }\end{array}$} & Yes & 779 (73.9\%) & 275 (26.1\%) & $<0.00 I^{*}$ \\
\hline & No & 1646 (83.9\%) & $317(16.1 \%)$ & \\
\hline
\end{tabular}

Note: $* \mathrm{P} \leq 0.05$. 
Table 3 Effect of Participants Characteristics on Anxiety

\begin{tabular}{|c|c|c|c|}
\hline & & Unadjusted OR $(95 \% \mathrm{Cl})$ & Adjusted OR $(95 \% \mathrm{Cl})$ \\
\hline Geographical region & $\begin{array}{l}\text { Middle } \\
\text { Eastern } \\
\text { Western } \\
\text { Northern } \\
\text { Southeast }\end{array}$ & $\begin{array}{c}\mathrm{I} \\
\mathrm{I} .5(1.18-1.83) \\
\mathrm{I} .7(1.17-2.35) \\
\mathrm{I} .7(1.13-2.45) \\
\mathrm{I} .3(0.82-2.17)\end{array}$ & $\begin{array}{c}1 \\
1.3(0.97-1.64) \\
1.0(0.62-1.48) \\
1.0(0.63-1.59) \\
0.7(0.38-1.22)\end{array}$ \\
\hline Sector & $\begin{array}{l}\text { Health sector } \\
\text { Education } \\
\text { Energy } \\
\text { Finance/Communication/Armed } \\
\text { forces } \\
\text { Other }\end{array}$ & $\begin{array}{c}\text { I.I }(0.84-1.50) \\
0.8(0.59-1.01) \\
\text { I.I }(0.69-1.73) \\
I .0(0.68-1.50) \\
I\end{array}$ & $\begin{array}{l}- \\
- \\
- \\
- \\
\end{array}$ \\
\hline Gender & $\begin{array}{l}\text { Male } \\
\text { Female }\end{array}$ & $\frac{1}{1.4(1.17-1.69)}$ & $\frac{\mathrm{I}}{\mathrm{I} . \mathrm{I}(0.89-\mathrm{I} .44)}$ \\
\hline Age & $\begin{array}{l}18-19 \\
20-29 \\
30-39 \\
40-49 \\
50-59 \\
60 \text { and above }\end{array}$ & $\begin{array}{l}5.6(2.79-11.22) \\
4.5(2.47-8.32) \\
4.1(2.21-7.46) \\
2.7(1.42-5.01) \\
1.8(0.92-3.39) \\
I\end{array}$ & $\begin{array}{c}3.2(0.66-15.58) \\
2.8(0.6 \mathrm{I}-12.75) \\
2.9(0.64-12.79) \\
1.9(0.43-8.78) \\
1.3(0.27-5.98) \\
\mathrm{I}\end{array}$ \\
\hline Marital Status & $\begin{array}{l}\text { Single } \\
\text { Married } \\
\text { Divorced/Widowed }\end{array}$ & $\begin{array}{c}\mathrm{I} \\
0.6(0.49-0.72) \\
0.7(0.44-1.18)\end{array}$ & $\begin{array}{c}\mathrm{I} \\
0.9(0.68-1.28) \\
1.1(0.58-2.16)\end{array}$ \\
\hline Education level & $\begin{array}{l}\text { School education } \\
\text { Diploma } \\
\text { Bachelor } \\
\text { Postgraduate }\end{array}$ & $\begin{array}{c}\text { I.2 }(0.85-1.60) \\
0.9(0.60-1.33) \\
\text { I.I }(0.84-1.4 I) \\
\text { I }\end{array}$ & $\begin{array}{l}- \\
- \\
- \\
-\end{array}$ \\
\hline Occupation & $\begin{array}{l}\text { Not currently employed } \\
\text { Student } \\
\text { Employee } \\
\text { Freelancer }\end{array}$ & $\begin{array}{c}1 \\
2.14(1.64-2.80) \\
1.44(1.16-1.80) \\
0.99(0.60-1.63)\end{array}$ & $\begin{array}{c}- \\
\text { I.2( }(0.57-2.33) \\
\text { I.I }(0.64-1.76) \\
\text { I }\end{array}$ \\
\hline $\begin{array}{l}\text { Work or study procedure after COVID-19 } \\
\text { outbreak }\end{array}$ & $\begin{array}{l}\text { Working from the office } \\
\text { Working from home } \\
\text { In paid Vacation } \\
\text { Studying from home }\end{array}$ & $\begin{array}{c}I \\
0.5(0.42-0.7 I) \\
0.8(0.56-I . I 2) \\
I . I(0.85-I .50)\end{array}$ & $\begin{array}{c}\mathrm{I} \\
0.5(0.37-0.66) \\
0.8(0.54-1.11) \\
0.7(0.44-1.23)\end{array}$ \\
\hline Household member & $\begin{array}{l}<5 \\
5-9 \\
>9\end{array}$ & $\begin{array}{c}\text { I.I }(0.80-1.45) \\
\text { I.I }(0.82-1.38) \\
\text { I }\end{array}$ & $\begin{array}{l}- \\
- \\
-\end{array}$ \\
\hline $\begin{array}{l}\text { Any household member under increased risk of } \\
\text { COVID-19? }\end{array}$ & $\begin{array}{l}\text { Yes } \\
\text { No }\end{array}$ & $\begin{array}{c}1.8(1.53-2.20) \\
1\end{array}$ & $\begin{array}{c}1.8(1.42-2.22) \\
\text { । }\end{array}$ \\
\hline
\end{tabular}

\section{Discussion}

This study aimed to evaluate the Saudi population's anxiety levels amid the lockdown period in May 2020. This study's findings suggest a significant increase in anxiety disorder, as $18.99 \%$ of the participants had moderate to severe anxiety levels. This result indicates that the pandemic might have caused anxiety among the general public, which coincides with Wang, Pan, and Wan et al's study in China. ${ }^{4}$ Also, our finding coincides with Alkhamees that $24 \%$ of participants reported moderate to severe anxiety levels during the early stage of the pandemic. ${ }^{9}$ 
This research also indicates that the geographical area had a significant association with the anxiety level. Western, Northern, and Eastern regions of the country demonstrate a high anxiety level. This finding might be because both Western and Eastern Regions were the initial epicenters of the pandemic within Saudi Arabia, which subsequently led to the first enforced curfew to contain the outbreak in the Kingdom. The results of this study continue to be consistent with Wang et al, 2020, as it is also found that a higher level of anxiety resided in Wuhan, the epicenter of the pandemic in China.

This study also found a significant association between the sex and the level of anxiety reported by participants. The results indicate that females experienced a significantly higher level of anxiety than males. A previous study supported this finding, suggesting that females suffer a higher level of anxiety during an infectious outbreak. ${ }^{14}$ Students were also found to experience the highest level of anxiety compared to the other occupations, which could be attributed to schools and universities suspending traditional forms of education and shifted towards online portals and web-based applications. Thereby, the sudden changes, uncertainty, and potential negative impact of academic progression might explain the higher level of anxiety amongst students than other professions. Students' vulnerability to anxiety during an outbreak is consistent with previous research that revealed that students display a greater psychological impact during an outbreak that denotes a higher level of stress, anxiety, and depression. ${ }^{14}$

This study continues to reveal a significant association between age and anxiety level, as the highest percentage of anxiety is attributed to groups ages 18 to $19(28.8 \%)$ and ages 20 to $29(24.7 \%)$. Moreover, as age increases, the level of anxiety decreases. These findings indicate that younger age groups were at higher risk for anxiety. Henceforth, their mental health may require special consideration by decision makers when developing targeted policies and interventions for the younger populations.

A notable finding is that the presence of COVID-19 vulnerable household member is the most important factor in predicting anxiety during a pandemic. This finding supports the Arafa and colleagues study where participants reported that one of the reasons for their high anxiety levels was the presence of a chronically ill or elderly household member. $^{8}$

Finally, the results of this study were able to illuminate the degree of psychological impact from COVID-19, especially among the females and the youth population. The pandemic's repercussion may be due to the unique social phenomena created by the reaction to the outbreak, which resulted in unprecedented social policy responses. These social distancing policies included imposed curfews and suspension of educational classrooms, which led to unforeseeable social and economic effects. Therefore, there is a need for targeted conduct and interventions to improve mental health care and reduce anxiety amongst the population in general, especially with vulnerable groups identified in the current study.

This study had several limitations that mostly pertain to the scope and generalizability of the results. Since a snowball sampling strategy was adopted, the sample may not represent the general Saudi population as most respondents were recruited from the Eastern and Middle Regions of Saudi Arabia. Another limitation can be traced to the short data collection period rather than merely persisted for 15 days, which may not sufficiently assess the pandemic's long-term psychological effects. Lastly, the GAD-7 is a self-administered tool, and the anxiety levels may not align with the formal diagnosis by a mental health professional.

\section{Conclusions}

The rapid growth of COVID-19 cases in Saudi Arabia has introduced an unprecedented public mental health concern. According to the study results, most participants reported mild anxiety levels, followed by moderate anxiety levels and severe anxiety levels. Moreover, this study identified an association between high anxiety levels and different socio-demographic factors, including the population residing in Eastern, Northern, or Western Regions, being female, being divorced or single, and being a student. Additionally, one of the most important factors associated with the increased levels of anxiety is the presence of a family member who is vulnerable to COVID-19. These findings emphasize the need for targeted interventions to curb this public mental health crisis.

\section{Recommendations}

Despite the Saudi government's rigorous efforts to curb the spread of COVID-19, there was a limited focus on the mental health needs during this pandemic, particularly during the duration of the strict lockdown. Our findings promulgate the need to inculcate nation-wide strategies to enforce public health emergency preparedness plans to mitigate the adverse psychological effects during medical pandemics. For example, the Saudi Ministry of Health should invest in promoting accessible video conferencing 
platforms to deliver cognitive-behavioral therapy (CBT) treatment to citizens and residents. ${ }^{15}$ Furthermore,

Special considerations to target populations are crucial to address their unique mental health needs. For instance, providing adequate personal protective equipment to general practitioners to provide them with a better sense of safety while treating infected patients. ${ }^{16}$ Considerations should also be placed on younger populations who are more susceptible to the vulnerabilities of mental health issues by using online or smartphone-based psychoeducation to promote mental wellness.

\section{Data Sharing Statement}

The authors wish not to share the data due to its being analyzed for other research projects.

\section{Ethical Approval}

Ethical approval was obtained from the Institutional Review Board of Imam Abdulrahman Bin Faisal University (Reference Number: IRB-2020-03-153). All participants provided informed consent, and that this study was conducted in accordance with the Declaration of Helsinki.

\section{Acknowledgments}

We want to express our gratitude to Nora Althumiri from the Sharek Health Organization for her assistance in distributing the online survey to participants from all regions of Saudi Arabia.

\section{Author Contributions}

All authors made substantial contributions to conception and design, acquisition of data, or analysis and interpretation of data; took part in drafting the article or revising it critically for important intellectual content; agreed to submit to the current journal; gave final approval for the version to be published; and agreed to be accountable for all aspects of the work.

\section{Funding}

Funding: This work was supported by the Imam Abdulrahman Bin Faisal University COVID-19 fund [grant number Covid19-2020-024-CAMS].

\section{Disclosure}

The authors reported no conflicts of interest for this work.

\section{References}

1. CDC. Coronavirus Disease 2019 (COVID-19) [Internet]. Centers Dis Control Prevent. 2020.

2. Saudi Arabia announces first case of coronavirus [Internet]. Arab News; 2020. Available from: https://arab.news/6xyan. Accessed May 17, 2020.

3. Saudi Gazette. Saudi Arabia to enforce 24-hour curfew from May 23 to 27 - Saudi Gazette [Internet]; 2020. Available from: https://saudi gazette.com.sa/article/593034. Accessed February 28, 2021.

4. Wang C, Pan R, Wan X, et al. Immediate psychological responses and associated factors during the initial stage of the 2019 Coronavirus Disease (COVID-19) Epidemic among the General Population in China. Int J Environ Res Public Health. 2020.

5. Lai J, Ma S, Wang Y, et al. Factors associated with mental health outcomes among health care workers exposed to coronavirus disease 2019. JAMA Netw Open. 2020;3(3):e203976-e203976. doi:10.1001/ jamanetworkopen.2020.3976

6. Karpenko OA, Syunyakov TS, Kulygina MA, Pavlichenko AV, Chetkina AS, Andrushchenko AV. Impact of COVID-19 pandemic on anxiety, depression and distress - online survey results amid the pandemic in Russia. Consortium Psychiatricum. 2020;1(No2). Available from: https://www.consortium-psy.com/jour/article/view/ 28.

7. Temsah M-H, Al-Sohime F, Alamro N, et al. The psychological impact of COVID-19 pandemic on health care workers in a MERS-CoV endemic country. J Infect Public Health. 2020;13 (6):877-882. doi:10.1016/j.jiph.2020.05.021

8. Arafa A, Mohammed Z, Mahmoud O, Elshazley M, Ewis A. Depressed, anxious, and stressed: what have healthcare workers on the frontlines in Egypt and Saudi Arabia experienced during the COVID-19 pandemic? J Affect Disord. 2021;278:365-371. doi:10.1016/j.jad.2020.09.080

9. Alkhamees AA, Alrashed SA, Alzunaydi AA, Almohimeed AS, Aljohani MS. The psychological impact of COVID-19 pandemic on the general population of Saudi Arabia. Compr Psychiatry. 2020;102:152192. doi:10.1016/j.comppsych.2020.152192

10. Spitzer RL, Kroenke K, Williams JBW, Löwe B, Brief A. Measure for assessing generalized anxiety disorder: the GAD-7. Arch Intern Med. 2006;166(10):1092-1097. doi:10.1001/archinte.166.10.1092

11. Sawaya H, Atoui M, Hamadeh A, Zeinoun P, Nahas Z. Adaptation and initial validation of the Patient Health Questionnaire - 9 (PHQ-9) and the Generalized Anxiety Disorder - 7 Questionnaire (GAD-7) in an Arabic speaking Lebanese psychiatric outpatient sample. Psychiatry Res. 2016;239:245-252. doi:10.1016/j.psychres.2016. 03.030

12. AlHadi AN, AlAteeq DA, Al-Sharif E, et al. An Arabic translation, reliability, and validation of Patient Health Questionnaire in a Saudi sample. Ann Gen Psychiatry. 2017;16(1):32. doi:10.1186/s12991017-0155-1

13. Robert S. GAD-7 (General Anxiety Disorder-7) [Internet]. MDCalc; 2020. Available from: https://www.mdcalc.com/gad-7-generalanxiety-disorder-7. Accessed March 2, 2021.

14. Al-Rabiaah A, Temsah M-H, Al-Eyadhy AA, et al. Middle East Respiratory Syndrome-Corona Virus (MERS-CoV) associated stress among medical students at a university teaching hospital in Saudi Arabia. J Infect Public Health. 2020;13(5):687-691. doi:10.1016/j. jiph.2020.01.005

15. Ho CS, Chee CY, Ho RC. Mental health strategies to combat the psychological impact of COVID-19 beyond paranoia and panic. Ann Acad Med Singap. 2020;49(3):155-160. doi:10.47102/annalsacadmedsg.202043

16. Amerio A, Bianchi D, Santi F, et al. Covid-19 pandemic impact on mental health: a web-based cross-sectional survey on a sample of Italian general practitioners. Acta Biomed. 2020;91(2):83-88. doi:10.23750/abm.v91i2.9619 


\section{Publish your work in this journal}

The International Journal of General Medicine is an international, peer-reviewed open-access journal that focuses on general and internal medicine, pathogenesis, epidemiology, diagnosis, monitoring and treatment protocols. The journal is characterized by the rapid reporting of reviews, original research and clinical studies across all disease areas. The manuscript management system is completely online and includes a very quick and fair peer-review system, which is all easy to use. Visit http://www.dovepress.com/ testimonials.php to read real quotes from published authors. 